Supporting Information for

\title{
Low Temperature Chemical Vapor Deposition of Cuprous Oxide Thin Films Using a Copper(I) Amidinate
}

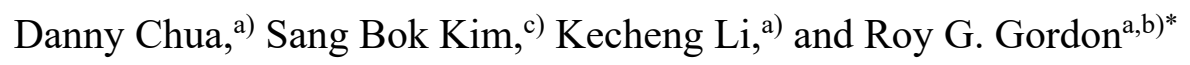

a) John A. Paulson School of Engineering and Applied Sciences, Harvard University, 29 Oxford Street, Cambridge, MA 02138, USA

b) Department of Chemistry and Chemical Biology, Harvard University, 12 Oxford Street, Cambridge, MA 02138, USA

c) Center for Educational Research, Seoul National University, 1 Gwanak-ro, Gwanak-gu, Seoul 08826, Korea

*Corresponding author: gordon@chemistry.harvard.edu

Table S1. Experimental conditions of CVD of $\mathrm{Cu} 2 \mathrm{O}$

\begin{tabular}{lll}
\hline CVD Parameters & Cuprous Oxide \\
\hline Cu & Precursor & $\left(N, N^{\prime}\right.$-di-sec-butylacetamidinato)copper(I) \\
& Temperature of Precursor Bubbler & $98^{\circ} \mathrm{C}$ \\
& Flow Rate of $\mathrm{N}_{2}$ Carrier Gas & $100 \mathrm{sccm}$ \\
O & Source & Deionized Water \\
& Temperature of Precursor Bubbler & $25{ }^{\circ} \mathrm{C}$ \\
& Flow Rate of $\mathrm{N}_{2}$ Carrier Gas & $5 \mathrm{sccm}$ \\
& \\
& \\
Flow Rate of $\mathbf{N}_{\mathbf{2}}$ Carrier Gas & $40 \mathrm{sccm}$ \\
Process Pressure & $1-10$ Torr \\
Substrate Temperature Window & $125-225{ }^{\circ} \mathrm{C}$ \\
\hline
\end{tabular}



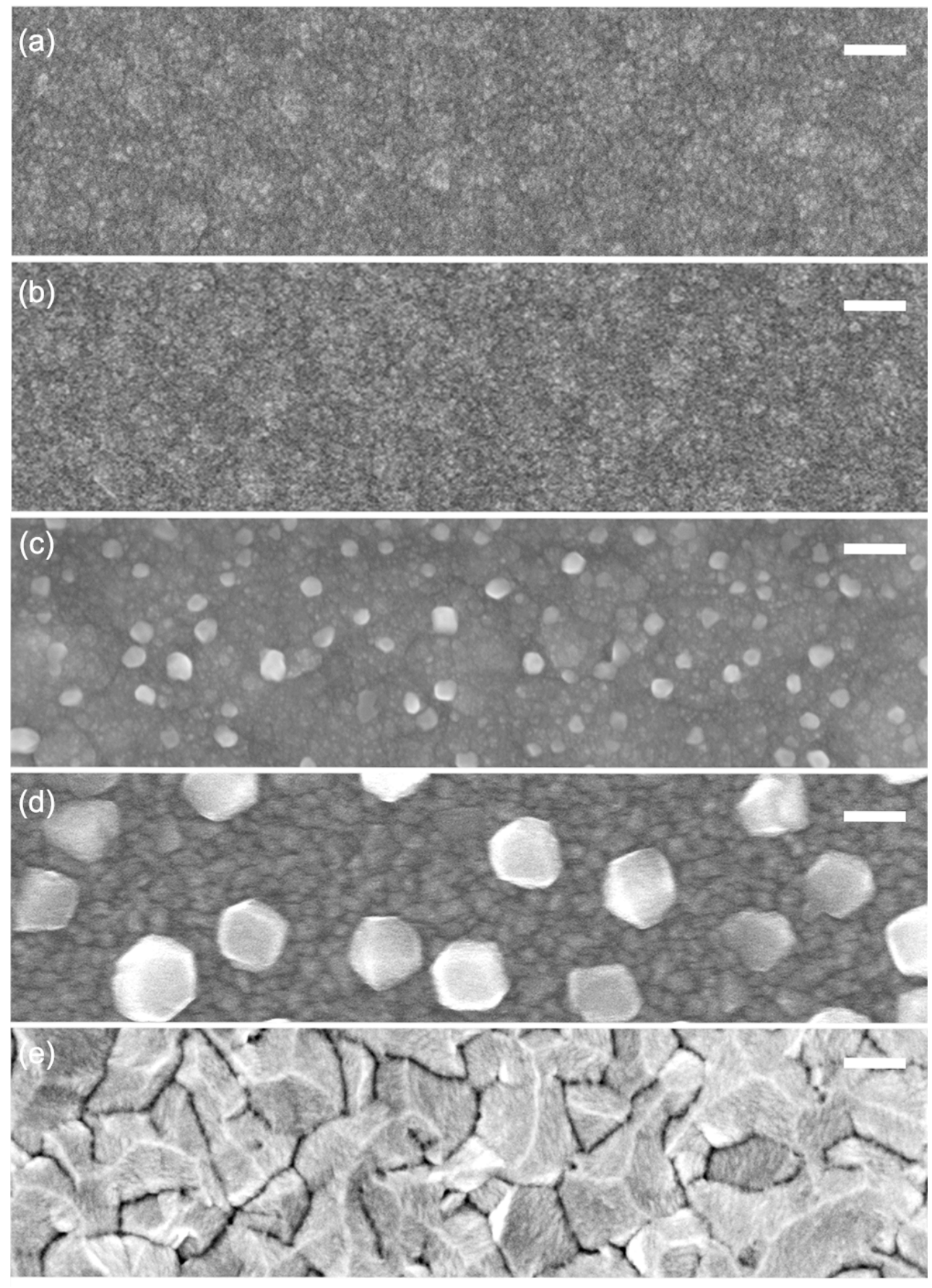

Figure S 1. Topological SEM images of $\mathrm{Cu}_{2} \mathrm{O}$ films deposited under smooth uniform growth conditions (process temperature of $175^{\circ} \mathrm{C}$ ) for thicknesses of (a) $80 \mathrm{~nm}$, and (b) $320 \mathrm{~nm}$ and deposited under high growth rate conditions (process temperature of $200^{\circ} \mathrm{C}$ ) for thicknesses of (c) $24 \mathrm{~nm}$, (d) $130 \mathrm{~nm}$, and (e) $1.8 \mu \mathrm{m}$. All scale bars represent $200 \mathrm{~nm}$. 